\title{
ASSOCIATION OF ACID-BASE PARAMETERS WITH LACTATE LEVEL IN CRITICALLY ILL PATIENTS WITH METABOLIC ACIDOSIS
}

\author{
Donaliazarti ${ }^{1}$, Rismawati Yaswir ${ }^{2}$, Hanifah Maani ${ }^{2}$, Efrida $^{2}$ \\ ${ }^{1}$ Faculty of Medicine and Health Sciences, Abdurrab University, Pekanbaru Indonesia. E-mail: donaliazarti@gmail.com \\ ${ }^{2}$ Department of Clinical Pathology, Faculty of Medicine andalas University/ Dr.M.Djamil Hospital, Padang, Indonesia. E-mail: \\ rismawatiyaswir@yahoo.com
}

\begin{abstract}
Metabolic acidosis is prevalent among critically ill patients and the common cause of metabolic acidosis in ICU is lactic acidosis. However, not all ICUs can provide lactate measurement. The traditional method that uses Henderson-Hasselbach equation (completed with $B E$ and $A G$ ) and alternative method consisting of Stewart and its modification ( $\mathrm{BDE}_{\text {gap }}$ and SIG), are acid-base balance parameters commonly used by clinicians to determine metabolic acidosis in critically ill patients. The objective of this study was to discover the association between acid-base parameters ( $B E, A_{\text {observed, }} A G_{\text {calculated, }} S I G, B D E_{\text {gap }}$ ) with lactate level in critically ill patients with metabolic acidosis. This was an analytical study with a cross-sectional design. Eighty-four critically ill patients hospitalized in the ICU department Dr. M. Djamil Padang Hospital were recruited in this study from January to September 2016. Blood gas analysis and lactate measurement were performed by potentiometric and amperometric method while electrolytes and albumin measurement were done by ISE and colorimetric method (BCG). Linear regression analysis was used to evaluate the association between acid-base parameters with lactate level based on p-value less than 0.05 . Fourty five (54\%) were females and thirty-nine (46\%) were males with participant's ages ranged from 18 to 81 years old. Postoperative was the most reason for ICU admission (88\%). Linear regression analysis showed that $p$-value for $B E, A G_{\text {observed, }} A G_{\text {calculated, }} S I G$ and $B D E_{\text {gap }}$ were $119 ; 0.967 ; 0.001 ; 0.001 ; 0.689$, respectively. Acid-base balance parameters which were mostly associated with lactate level in critically ill patients with metabolic acidosis were $A_{\text {calculated }}$ and SIG.
\end{abstract}

Key words: Metabolic acidosis, lactate, acid-base parameters, critically ill

\section{INTRODUCTION}

Acid-base imbalance is prevalent among critically ill patients. One study showed that metabolic acidosis affected $64 \%$ of critically ill patients. ${ }^{1}$ Metabolic acidosis is still a great marker of mortality in critically ill patients and requires early detection so that clinicians can give appropriate interventions and improve outcomes. ${ }^{2}$

Lactate is an organic acid that causes acidosis. The common cause of metabolic acidosis in the ICU is lactic acidosis. Lactate level in the blood becomes an indicator severity of the disease and related with outcome in critically ill patients. Elevated levels of lactic acid in critically ill patients is associated with hypoxia and inflammatory process. ${ }^{1,2}$ However, measurements of lactic acid are not easily available in all ICUs, so acid-base balance parameters are used to predict lactate level. ${ }^{3}$

Acid-base imbalance can be described by traditional method and alternative method. HendersonHasselbalch equation becomes a basic calculation for traditional method which completed with BE and AG. Alternative method (Stewart and its modification) is based on $\mathrm{BDE}_{\text {gap }}$ and SIG calculation. ${ }^{4}$ Different methods used in diagnosing acid-base imbalance will give various interpretations and treatments which are different although for the same disorder. Traditional method can identify causes of metabolic acidosis but it is only based on AG, so it still coveres a fairly extensive situation. Alternative method is able to assess small changes in ion levels that has a role in acid-base balance, which is unrecognized by traditional method. $^{2}$ 
Henderson-Hasselbalch equation shows the role of bicarbonate-carbonic acid buffer system by using $\mathrm{PaCO}_{2}$ and $\mathrm{HCO}_{3}$ - as an independent variable for $\mathrm{pH}^{5}$ The lack of this method is the dependence of $\mathrm{HCO}_{3}$ - serum level toward $\mathrm{PaCO}_{2}$ and it is difficult to detect acid-base imbalance in complex metabolic situations especially for critically ill patients. ${ }^{4,6}$

Siggaard-Anderson completed HendersonHasselbalch equation with BE calculation. Base excess is the amount of acid or alkali that have to be added into $1 \mathrm{~L}$ of whole blood to balance blood $\mathrm{pH}$ to be 7.4 in $\mathrm{PaCO}_{2} 40 \mathrm{mmHg} .{ }^{4,7}$ Base excess calculation shows the final effect of all acid-base imbalance and does not indicate etiology. Acidosis and alkalosis that occur simultaneously will give overlapping result and misinterpretation as a result of no acid-base imbalance. $^{8}$

Anion gap ( $\left.A G_{\text {observed }}\right)$ calculation will be added to metabolic acidosis diagnosis. Anion gap is a gap between amount of anions and cations in the body and shows the level of anions that are not measured in plasma which is mostly albumin. Hypoalbuminemia might cause the low of $A G$ value so it is important to correct it $\left(A G_{\text {calculated }}\right)$ toward the patient's serum albumin level. ${ }^{4}$ Anion gap has a weakness that it is not able to identify acid-base imbalance induced by alteration in plasma free water. ${ }^{8}$

Alternative method (Stewart) reveals that $\mathrm{H}^{+}$ concentration in a solution is affected by the degree of water dissociation into $\mathrm{H}^{+}$and $\mathrm{OH}^{-}$. Three independent variables that affect water dissociation are strong ion difference (SID), $\mathrm{PaCO}_{2}$ and total weak acid (Atot). ${ }^{9,10}$ Alternative method (Stewart) is difficult to apply because it has many variables that have to be measured and calculated so the experts developed a simplified Stewart method including Fencl-Stewart and Figge-Stewart. ${ }^{6,11,12}$ Fencl-Stewart method calculates $\mathrm{BDE}_{\text {gap }}$ based on $\mathrm{Na}^{+}, \mathrm{Cl}^{-}$and albumin concentrations. Figge-Stewart method calculated SIG (the difference between apparent SID/ SIDa and effective SID/SIDe) showing there are other unmeasured strong ions. ${ }^{10,12}$

Several studies have been conducted to determine acid-base balance parameters that mostly related with lactate level in critically ill patients. ${ }^{1,2}$ Rocktaeschel et al. Found that $\mathrm{BE}, \mathrm{BDE}_{\text {gap }}$ and $\mathrm{AG}$ were good predictors of hyperlactatemia. ${ }^{3}$ Balasubramanyan et al. Found that $\mathrm{BDE}_{\text {gap }}$ was better than $A G$ and $B E$ for identifying high lactate level in critically ill patients. ${ }^{13}$
Clinicians need to be aware of lactic acidosis in critically ill patients in order to provide appropriate therapy and reduce mortality rates. A number of parameters has been known to evaluate acid-base imbalance but the best parameter as predictor of lactic acid level is still being debated. Based on the above mentioned, we are interested to investigate association between parameters of acidbase balance (BE, $A G_{\text {observed, }} \mathrm{AG}_{\text {calculated, }} \mathrm{SIG}$ and $\mathrm{BDE}_{\text {gap }}$ ) with lactate level in critically ill patients who have metabolic acidosis in ICU Dr. M. Djamil Hospital, Padang.

\section{METHODS}

This was an analytical study with a crosssectional design. The study was performed on critically ill patients treated in the ICU from January to September 2016. The study took place in the Emergency Laboratory and ICU of Dr. M. Djamil Hospital, Padang. Institutional Ethics Committee Faculty of Medicine Andalas University had approved this study. Informed consent was waived because laboratory test and data taken were part of routine clinical practice.

The samples of the research were critically ill patients (based on APACHE score) in the ICU who underwent blood gas analysis and clinical chemistry examination at the Emergency Laboratory of Dr. M. Djamil Hospital, Padang within 24 hours of admission that fit inclusion and exclusion criteria. Patients with age $>18$ years and had blood $\mathrm{pH}<7.35$ were included in this study. Patients were excluded if they had respiratory acidosis. Sample selection was performed by consecutive sampling.

This study used two types of specimens. First, venous blood was collected in vacutainers without anticoagulant and left at room temperature for one hour to form a clot. The specimen was then centrifuged at $3500 \mathrm{rpm}$ for 15 minutes to obtain serum for electrolytes $\left(\mathrm{Na}^{+}, \mathrm{K}^{+}, \mathrm{Cl}^{-}\right)$and albumin examination with ISE and colorimetric methods respectively. Second, arterial blood was drawn in the syringe that had been rinsed with anticoagulant sodium heparin 1000 units $/ \mathrm{mL}$ for blood gas analysis $\left(\mathrm{pH}, \mathrm{PaCO}_{2}, \mathrm{HCO}_{3}^{-}, \mathrm{BE}\right), \mathrm{Ca}^{2+}$, lactate and performed by potentiometric and amperometric methods. Data from those examinations were used to calculate $A G_{\text {observed, }} A_{\text {calculated, }} \mathrm{BDE}_{\text {gap }}$ and $\mathrm{SIG}$. Data analysis were completed by SPSS version 18.0. Descriptive data with normal distribution were presented in 
mean and Standard Deviation (SD) or median and Interquartile Range (IQR) for abnormal distribution. A multivariate analysis was conducted to determine the association of acid-base balance parameters ( $\mathrm{BE}, \mathrm{AG}_{\text {observed, }} \mathrm{AG}_{\text {calculated, }} \mathrm{BDE}_{\text {gap }}, \mathrm{SIG}$ ) and lactate level using linear regression analysis. The acid-base parameter with most significant $p$-value was the best parameter that related to the lactate level.

\section{RESULTS AND DISCUSSION}

Eighty-four patients participated in this study. The general characteristics of patients and the results of acid-base balance parameters and lactate level can be seen in Table 1 and 2 . and 2.43, respectively. The median value of $B E$, $A G_{\text {observed, }} A_{G_{\text {calculated, }}, B D E_{\text {gap }},} \mathrm{SIG}$ and lactate were $8.55 ; 13.8 ; 18.53 ; 2.76 ; 7.77$; and 3.25 , respectively. Pvalue for linear regression analysis between acid-base balance parameters ( $\mathrm{BE}, \mathrm{AG}_{\text {observed, }} \mathrm{AG}_{\text {calculated }} \mathrm{BDE}_{\text {gap }}$ and SIG) with lactate level was shown in Table 3.

Base excess is the amount of acid or alkali that has to be added to $1 \mathrm{~L}$ of whole blood to balance blood $\mathrm{pH}$ to 7.4 in $\mathrm{PaCO}_{2} 40 \mathrm{mmHg}$. The negative value of $\mathrm{BE}$ ( $<-2 \mathrm{mmol} / \mathrm{L})$ is acidosis. ${ }^{4,7}$ Multivariate analysis showed that BE did not associate with lactate level. The weaknesses of $B E$ represent the last effect of all acid-base imbalance and does not indicate etiology. Acidosis and alkalosis occurring simultaneously will give overlapping results and misinterpretation, as a

Table 1. General characteristics of patients

\begin{tabular}{|c|c|c|c|}
\hline Characteristics & n (\%) & Range & $X(S D)$ \\
\hline Age (years) & & $18-81$ & $44.4 \pm 18$ \\
\hline \multicolumn{4}{|l|}{ Gender } \\
\hline Male & $39(46)$ & & \\
\hline Female & $45(54)$ & & \\
\hline \multicolumn{4}{|c|}{ Reasons for ICU admission: } \\
\hline Post-operative & $74(88)$ & & \\
\hline Others & $19(12)$ & & \\
\hline
\end{tabular}

SD : Standard Deviation

Table 2. Acid-base balance parameters and lactate level of patients

\begin{tabular}{|c|c|c|c|c|}
\hline \multirow{2}{*}{ Variables } & \multicolumn{2}{|c|}{ Range } & \multirow{2}{*}{$\begin{array}{c}x \\
\text { (SD) }\end{array}$} & \multirow[t]{2}{*}{ Median (IQR) } \\
\hline & Min & Max & & \\
\hline \multicolumn{5}{|l|}{ Measured variables } \\
\hline $\mathrm{Na}^{+}(\mathrm{mmol} / \mathrm{L})$ & 121 & 157 & $134.49(6.68)$ & \\
\hline $\mathrm{K}^{+}(\mathrm{mmol} / \mathrm{L})$ & 2.0 & 7.0 & $4.19(0.97)$ & \\
\hline $\mathrm{Cl}^{-}(\mathrm{mmol} / \mathrm{L})$ & 95 & 125 & $106.74(5.74)$ & \\
\hline $\mathrm{Ca}^{2+}(\mathrm{mmol} / \mathrm{L})$ & 0.22 & 1.01 & $0.63(0.16)$ & \\
\hline Albumin (g/dL) & 0.7 & 4.0 & $2.43(0.79)$ & \\
\hline Lactate (mmol/L) & 0.4 & 15.0 & & 3.25 (2.9) \\
\hline \multicolumn{5}{|l|}{ Calculated variables } \\
\hline $\mathrm{HCO}_{3}^{-}(\mathrm{mmol} / \mathrm{L})$ & 3.0 & 24.8 & $17.14(4.53)$ & \\
\hline $\mathrm{BE}(\mathrm{mmol} / \mathrm{L})$ & -29.8 & -1.0 & & $-8.55(5.3)$ \\
\hline $\mathrm{AG}_{\text {observed }}(\mathrm{mmol} / \mathrm{L})$ & 4.4 & 44.4 & & $13.8(5.7)$ \\
\hline $\mathrm{AG}_{\text {calculated }}(\mathrm{mmol} / \mathrm{L})$ & 8.2 & 47.65 & & $18.53(6.31)$ \\
\hline $\mathrm{BDE}_{\text {gap }}(\mathrm{mmol} / \mathrm{L})$ & -28.33 & 12.70 & & $2.76(7.15)$ \\
\hline $\mathrm{SIG}(\mathrm{mmol} / \mathrm{L})$ & -2.8 & 36.42 & & $7.77(6.44)$ \\
\hline
\end{tabular}

SD: Standard Deviation; IQR: Interquartile Range

Table 1 showed that the average of patients age was 44 years. They consisted of females (54\%) and males (46\%). Most of the patients admitted to ICU were caused by a post-operative condition (88\%). The average value of $\mathrm{HCO}_{3}{ }^{-}, \mathrm{Na}^{+}, \mathrm{K}^{+}, \mathrm{Cl}^{-}, \mathrm{Ca}^{2+}$ and albumin were $17.14 ; 134.49 ; 4.19 ; 106.74 ; 0.63$; and 2.43 , respectively. The median value of $B E$, result there is no acid base imbalance. ${ }^{8}$

Multivariate analysis showed $\mathrm{AG}_{\text {observed }}$ had no relationship with lactate level. Anion gap $\left(A G_{\text {observed }}\right)$ represent the gap between amount of anions and cations in the body. Increasing $\mathrm{AG}_{\text {observed }}$ indicate acidosis due to an addition of other strong anions derived from organic acids including lactic acid, but 
derived from organic acids including lactic acid, but $A G_{\text {observed }}$ has a weakness because it has not been corrected by albumin level that causes the falseness of low AG. ${ }^{4}$

Table 3. Linear regression analysis between acid-base balance parameters with a lactate level

\begin{tabular}{lc}
\hline Parameters & Lactate level $(\mathbf{p})$ \\
\hline $\mathrm{BE}(\mathrm{mmol} / \mathrm{L})$ & 0.119 \\
$\mathrm{AG}_{\text {observed }}(\mathrm{mmol} / \mathrm{L})$ & 0.967 \\
$\mathrm{AG}_{\text {calculated }}(\mathrm{mmol} / \mathrm{L})$ & 0.001 \\
$\mathrm{BDE}_{\text {gap }}(\mathrm{mmol} / \mathrm{L})$ & 0.689 \\
$\mathrm{SIG}(\mathrm{mmol} / \mathrm{L})$ & 0.001 \\
\hline
\end{tabular}

Multivariate analysis showed BDEgap had no relationship with lactate level. This might be due to $\mathrm{BDE}_{\text {gap }}$ as a calculation to determine acid-base balance disorders that have been simplified. $\mathrm{BDE}_{\text {gap }}$ does not calculate most of the ions that have a role in acid-base balance and only based on $\mathrm{Na}^{+}, \mathrm{Cl}^{-}$and albumin concentration. ${ }^{12}$

This study revealed that $A G_{\text {calculated }}$ and SIG had the most significant association $(p=0.001)$ with lactate level compared to other parameters (BE, $\left.A G_{\text {observed }}, B D E_{\text {gap }}\right)$. It showed that $A G_{\text {calculated }}$ and SIG were acid-base balance parameters which could be predictors of hyperlactatemia in critically ill patients who had metabolic acidosis in ICU. Increasing $A G_{\text {calculated }}$ and SIG have the same meaning. Both of them indicate acidosis due to an addition of other strong anions derived from organic acids including lactic acid, but the calculation was different.

Anion gap $\left(\mathrm{AG}_{\text {calculated }}\right)$ is a corrected value of $\mathrm{AG}_{\text {observed }}$ with patients albumin level. ${ }^{4}$ Strong ion gap is a modified Stewart method to investigate the acid-base imbalance which is calculated based on the difference between SIDa and SIDe. ${ }^{14-16}$ Strong ion different apparent counts the number of strong ions. SIDa formula in this study is $\left[\mathrm{Na}^{+}\right]+\left[\mathrm{K}^{+}\right]+$ $\left[\mathrm{Ca}^{2+}\right]-\left[\mathrm{Cl}^{-}\right]$. This will be balanced by negative charge called SIDe. SIDe formula in this study is $\left[\mathrm{HCO}_{3}{ }^{-}\right]+$[albumin charge].

Other studies showed different results, Rocktaeschel et al. Found that BE, BDEgap and AG were good predictors of hyperlactatemia. ${ }^{3}$ Balasubramanyan et al. Found that BDEgap was better than $A G$ and $B E$ in identifying lactate level in critically ill patients. ${ }^{13}$ Mikulaschek et al., discovered that $A G$ and $B E$ were not able to predict lactate level. ${ }^{17}$ Iberti et al. Showed that AG was a poor parameter for detection hyperlactatemia in critically ill patients. ${ }^{18}$

This condition might be caused by differences in patient criteria of each study. This study was performed on critically ill patients who had metabolic acidosis in the ICU while other studies were performed in all critically ill patients. Another cause was the difference between number and type of ions that could be measured in each study that affects the formula used.

The measurement methods of each ion/ analyte were also different in many studies because it depended on the conditions of each study. Differences in the place of research and Standard Operating Procedure (SOP) led to differences in initial treatment (resuscitation fluid) which was given before ICU admission. The different types of fluid resuscitation led to ion changes in the patient's body and affected the acid-base balance. The different types of specimens (plasma/serum/whole blood) used in each study also affected the ion levels which were examined.

This study had limitations because it did not measure sulfates, phosphates, ketones and magnesium as other causes of increasing of strong ions in the body. The gold standards for measuring each ion/analyte that were required in the calculation of acid-base balance parameters had not been used because they were not available in this study. Reference value was taken from a manual book that examined different populations because there was no reference value in our population. Initial therapies which were given to patients before ICU admission were also not considered.

\section{CONCLUSION AND SUGGESTION}

Acid-base balance parameters which mostly associated with lactate level in critically ill patients, who have metabolic acidosis, in the ICU Dr. M. Djamil Hospital, Padang were $\mathrm{AG}_{\text {calculated }}$ and SIG. Further research should be conducted in place with adequate facilities to measure all the ions/analytes that play a role in metabolic acidosis and healthy controls need to be participating in the next research to obtain a normal range of reference values. Further research should be carried out using standard methods for the examination of ion/analyte included in the calculation of acidbase balance parameters and it is important to consider drug or fluid administered before the patient is admitted to ICU. 


\section{REFERENCES}

1. Jaghbeer MA \& Kellum JA. Acid-Base Disturbances in Intensive Care Patients: Etiology, Pathophysiology and Treatment. Nephrol Dial Transplant. 2015; 30(7): 1104-11.

2. Gunnerson KJ. Clinical Review: The Meaning of Acid -Base Abnormalities in The Intensive Care UnitEpidemiology. Crit Care. 2005; 9(5): 508-16.

3. Rocktaeschel J, Morimatsu H, Uchino S, Bellomo R. Unmeasured Anions in Critically III Patients: Can They Predict Mortality? Crit Care Med. 2003; 31(8): 2131-6.

4. Dubin A, Menises MM, Masevicius FD, Moseinco MC, Kutscherauer DO, Ventrice E et al. Comparison of Three Different Methods of Evaluation of Metabolic Acid-Base Disorders. Crit Care Med. 2007; 35(5): 1264-70.

5. Rastegar A. Clinical Utility of Stewart's Method in Diagnosis and Management of Acid-Base Disorders, Clin J Am Soc Nephrol. 2009; 4(7): 1267-74.

6. Sinaga R, Sukadi A, Somasetia DH. Agreement of Simplified Fencl-Stewart with Figge-Stewart Method in Diagnosing Metabolic Acidosis in Critically III Children. Paediatrica Indonesiana. 2007; 47(4): 144-9.

7. Barthwal MS. Analysis of Arterial Blood Gases-A Comprehensive Approach. JAPI. 2004; 52: 573-77.

8. Fidkowski C \& Helstrom J. Diagnosing Metabolic Acidosis in The Critically III: Bridging the Anion Gap, Stewart and Base Excess Methods. Can J Anaesth. 2009; 56(3): 247-56.

9. Story DA, Poustie S, Bellomo R. Quantitative Physical Chemistry Analysis of Acid-Base Disorders in Critically III Patients. Anesthesia. 2001; 56(6): 530 $-3$.

10. Darwis D, Moenadjat Y, Madjid AS, Siregar P, Wibisono LK, Mudjihartini $\mathrm{N}$ et al. Gangguan Keseimbangan Air Elektrolit dan Asam Basa: Fisiologi, Patofisiologi, Diagnosis, dan Tatalaksana. Ed ke-3., Jakarta, Badan Penerbit Fakultas Kedokteran Universitas Indonesia. 2012; 147-68.
11. Rocktaeschel J, Morimatsu H, Uchino S, Goldsmith D, Poustie S, Story D et al. Acid-Base Status of Critically III Patients with Acute Renal Failure: Analysis Based on Stewart-Figge Methodology. Crit Care. 2003; 7(4): R606.

12. Story DA, Morimatsu H, Bellomo R. Strong lons, Weak Acids and Base Excess: A Simplified Fencl-Stewart Approach to Clinical Acid-Base Disorders. British J of Anaesthesia. 2004; 92(1): 54-60.

13. Balasubramanyan $\mathrm{N}$, Havens PL, Hoffman $\mathrm{G}$. Unmeasured Anions Identified by Fencl-Stewart Method Predict Mortality Better than Base Excess, Anion Gap and Lactate in Patients in Pediatric Intensive Care Unit. Critical Care Medicine. 1999; 27(8): 1577-81.

14. Kaplan $U$ \& Frangos S. Clinical Review: Acid-Base Abnormalities in The Intensive Care Unit. Crit Care. 2005; 9(2): 198-203.

15. Darmawan I. Stewart Approach in Acid-Base Balance. 2014, diunduh dari pt.slideshare.net, dilihat tanggal 20/05/2016.

16. Gezer M, Bulucu F, Ozturk K, Kilic S, Kaldirim U, Eyi YE. Effectiveness of The Stewart Method in The Evaluation of Blood Gas Parameters. Turk J Emerg Med. 2015; 15 (1): 3-7.

17. Mikulaschek A, Henry SM, Donovan R, Scalea TM. Serum Lactate is not Predicted by Anion Gap or Base Excess after Trauma Resuscitation. J Trauma. 1996; 40 (2): 218-22.

18. Iberti TJ, Leibowitz AB, Papadakos PJ, Fischer FP. Low Sensitivity of the Anion Gap as A Screen to Detect Hyperlactatemia in Critically III Patients. Crit Care Med. 1990; 18(3): 275-7. 